\title{
Air Pollution and Urban Green Space: Evidence of Environmental Injustice in Adama, Ethiopia
}

\author{
Erin Flanagan ${ }^{1 *}$, Kristoffer Mattisson ${ }^{1}$, John Walles ${ }^{2,3}$, Asmamaw Abera ${ }^{4,5}$, Axel Eriksson ${ }^{6}$, \\ Festina Balidemaj ${ }^{1}$, Anna Oudin ${ }^{1}$, Christina Isaxon ${ }^{6}$ and Ebba Malmqvist ${ }^{1}$ \\ ${ }^{1}$ Division of Occupational and Environmental Medicine, Department of Laboratory Medicine, Faculty of Medicine, Lund \\ University, Lund, Sweden, ${ }^{2}$ Clinical Infection Medicine, Department of Translational Medicine, Faculty of Medicine, Lund \\ University, Malmö, Sweden, ${ }^{3}$ Department of Infectious Diseases, Central Hospital Kristianstad, Kristianstad, Sweden, ${ }^{4}$ Water \\ and Public Health Department, Ethiopia Institute of Water Resources, Addis Ababa University, Addis Ababa, Ethiopia, \\ ${ }^{5}$ Department of Non-Communicable Diseases, Armauer Hansen Research Institute, Addis Ababa, Ethiopia, ${ }^{6}$ Division of \\ Ergonomics and Aerosol Technology, Department of Design Sciences, Faculty of Engineering, Lund University, Lund, Sweden
}

While air pollution data in Ethiopia is limited, existing studies indicate high levels of both ambient and household air pollution; rapid urbanization also threatens the preservation of urban green spaces. In this study, environmental injustice, or the disproportionate burden of environmental exposures on persons of lower socioeconomic status (SES), was explored among women in Ethiopia using a mother and child cohort from the

OPEN ACCESS

Edited by:

Heran Zheng,

Norwegian University of Science and

Technology, Norway

Reviewed by:

Yuan Shi,

The Chinese University of Hong Kong, Hong Kong, SAR China Ashraf Dewan,

Curtin University, Australia

*Correspondence: Erin Flanagan erin.flanagan@med.lu.se

Specialty section:

This article was submitted to Climate Change and Cities,

a section of the journal

Frontiers in Sustainable Cities

Received: 21 June 2021

Accepted: 27 August 2021 Published: 22 September 2021

Citation:

Flanagan E, Mattisson K, Walles J, Abera A, Eriksson A, Balidemaj F, Oudin A, Isaxon $C$ and Malmqvist $E$ (2021) Air Pollution and Urban Green

Space: Evidence of Environmental Injustice in Adama, Ethiopia. Front. Sustain. Cities 3:728384. doi: 10.3389/frsc.2021.728384 city of Adama. Land-use regression models were previously developed for modeling ambient nitrogen dioxide $\left(\mathrm{NO}_{2}\right)$ and nitrogen oxides $\left(\mathrm{NO}_{\mathrm{x}}\right)$ throughout Adama, while household air pollution (cooking fuel type) and the presence of green space were assessed through questionnaires and home visits, respectively. The odds of being exposed to these environmental factors were analyzed in association with two SES indicators, education and occupation, using logistic regression. Our results indicate the presence of environmental injustice in Adama, as women with lower SES shouldered a higher burden of air pollution exposure and enjoyed less urban green space than their higher SES counterparts. These findings encourage the prioritization of air quality control and urban planning resources toward policy action within lower SES areas. From a societal perspective, our results also support more upstream interventions, including investment in educational and occupational opportunities. Still, a human rights approach is emphasized, as governments are responsible for protecting the right to a clean environment, especially for those disproportionately exposed. To the best of our knowledge, this is the first study on environmental injustice in Ethiopia, and the first in Sub-Saharan Africa to investigate the inequalities of ambient and household air pollution exposure as well as urban green space access in the same cohort.

Keywords: environmental injustice, exposure inequality, socioeconomic status, ambient air pollution, household air pollution, urban green space

\section{INTRODUCTION}

Expansive scientific literature on air pollution and health has led to an understanding of its role in countless illnesses and diseases (World Health Organization, 2016a; Landrigan et al., 2017), such as respiratory disease (World Health Organization, 2013a,b; Castro et al., 2017), cardiovascular (Chen and Hoek, 2020) and cerebrovascular disease 
(Niu et al., 2021), pregnancy complications (Pedersen et al., 2014), adverse birth outcomes (Stieb et al., 2012; Perera et al., 2019), childhood asthma (Khreis et al., 2017), neurological and developmental disorders (Chun et al., 2020), dementia (Carey et al., 2018), and even death (Hoek et al., 2013; Huangfu and Atkinson, 2020). Indeed, it is estimated that mortality due to ambient air pollution alone is likely to increase by $50 \%$ or more by 2050 if no aggressive mitigating actions are taken (Lelieveld et al., 2015).

In Sub-Saharan Africa, one of the greatest contributors to ambient air pollution is traffic (Hitchcock et al., 2014), particularly from an old and poorly maintained vehicle fleet (Panyacosit, 2000). Many countries, including Japan and European nations, regularly export cars to Africa that no longer meet their own environmental standards, so-called "superemitters" (Brunekreef, 2005), oftentimes after removing their particle filters and catalytic converters (Naidja et al., 2018). Samples of particulate matter (PM) taken from roadsides in Addis Ababa, Ethiopia, for example, were found to contain toxic elements including lead, zinc, cadmium, and chromium (Embiale et al., 2019), yet emissions from vehicle exhaust are not systematically regulated in most African countries (Naidja et al., 2018). Another important source of outdoor air pollution is solid waste burning (Naidja et al., 2018), as waste collection and transport services are often lacking (Solomon, 2011). This practice emits harmful pollutants, such as heavy metals (Wang et al., 2017), polycyclic aromatic hydrocarbons (PAHs) (Hsu et al., 2016), and dioxins (Li et al., 2019).

Household air pollution is also a prominent issue in SubSaharan Africa, as pollutive biomass fuels are often used for cooking and heating (Mead et al., 2008; World Health Organization, 2016b; Naidja et al., 2018). Burning solid fuels like wood, charcoal, animal dung, and crop residue in traditional cooking stoves emits high levels of PM, PAHs, and carbon monoxide (CO) (Naidja et al., 2018). Studies from Addis Ababa, Ethiopia, have identified indoor PM concentrations of 818$905 \mu \mathrm{g} / \mathrm{m}^{3}$ (Keil et al., 2010; Sanbata et al., 2014), which is $\sim 30$ times higher than residential averages in high-income countries (Morawska et al., 2013). These exposures tend to disproportionately affect women, whom are most often tasked with cooking, and their children (Okello et al., 2018; Mocumbi et al., 2019).

Importantly, household and ambient air pollution co-exist: emissions from cooking contribute to overall ambient air pollution levels, and ambient air pollution contributes to household air pollution (Bo et al., 2017; Balmes, 2019), especially when homes are not well-insulated or home filtration systems of the outdoor air are not available. While air pollution data in Ethiopia is limited, existing studies indicate high levels of both ambient and household air pollution to be a significant problem (Tefera et al., 2016).

Moreover, rapid urbanization occurring throughout SubSaharan Africa (UNEP, 2014; Pieterse et al., 2015) can intensify environmental burdens. Fueling this urbanization is general population growth, with the region as a whole experiencing an annual population growth of $2.6 \%$ as of 2020 (The World Bank, 2021). Anthropogenic sources of air pollution, such as traffic, waste burning, solid fuel combustion, and industry, and their subsequent health effects (Owili et al., 2017), are likely to increase with an increasing urban population. Additionally, this growth often happens faster than infrastructure can accommodate. The potential "coordination deficit" (Hill et al., 2014) poses a risk to urban green areas and existing biodiversity there within (Güneralp et al., 2017; Ofori et al., 2018), as buildings and other supporting structures are constructed- at times without adequate planning. Studies from other parts of the world (Lee and Maheswaran, 2011; Saulle and La Torre, 2011) and South Africa (Tomita et al., 2017) have found that green spaces, particularly in urban environments, have ameliorating effects on mental health and well-being and facilitate physical activity and social contact (World Health Organization, 2016c). Unfettered urban development that cuts into greenery can also exacerbate the heat island effect (Taha, 1997; Mohajerani et al., 2017), which negatively impacts both human health and the climate. Despite its importance, relatively few studies have been conducted in Sub-Saharan Africa investigating green space in connection to humans, such as residential access and health benefits.

Environmental injustice, or environmental inequity, is the unequal distribution of environmental burdens among areas characterized by lower socioeconomic status (SES). A 2015 global review reported a consistent air pollution exposure gradient among studies conducted in North America, Asia and Oceania, with exposure increasing as SES decreased (Hajat et al., 2015). Only findings from European settings appeared to be mixed (Hajat et al., 2015), as historic city centers, sometimes having higher levels of air pollution, increase property values and attract higher-income residents (O’Neill et al., 2003). Most research concerning environmental injustice has been conducted in high-income or upper-middle-income countries despite lower-income countries (LICs) and lower-middle-income countries (LMICs) often facing higher air pollution exposure and greater threats to urban green space retention. A recent study in India adds new evidence on this relationship within LMICs: areas populated by persons of lower castes, whom have been traditionally marginalized, and neighborhoods with poor sanitation and housing conditions were subjected to higher concentrations of PM with an aerodynamic diameter $<2.5 \mu \mathrm{m}$ $\left(\mathrm{PM}_{2.5}\right)$ (Chakraborty and Basu, 2021).

A clear knowledge gap exists, as few studies on environmental injustice related to air pollution exposure have been conducted in Africa. Of 37 studies evaluated in a global review on environmental injustice (Hajat et al., 2015), only one conducted in Africa was identified. Based in Ghana, its results indicated that higher SES areas were associated with lower concentrations of $\mathrm{PM}_{2.5}$ and $\mathrm{PM}$ with an aerodynamic diameter $<10 \mu \mathrm{m}\left(\mathrm{PM}_{10}\right)$ (Rooney et al., 2012). Regarding the unequal experience of urban green areas, a study from Nigeria demonstrated that $65 \%$ of persons living in low-income residential areas were dissatisfied with their access to green space, whereas dissatisfaction dropped to $28 \%$ in middle-income neighborhoods and to only $8 \%$ in highincome areas (Ochodo et al., 2014). An understanding of the socioeconomic differences in exposure can shape future health impact assessments, inform policy decisions, and identify priority intervention groups. To the best of our knowledge, no study to 


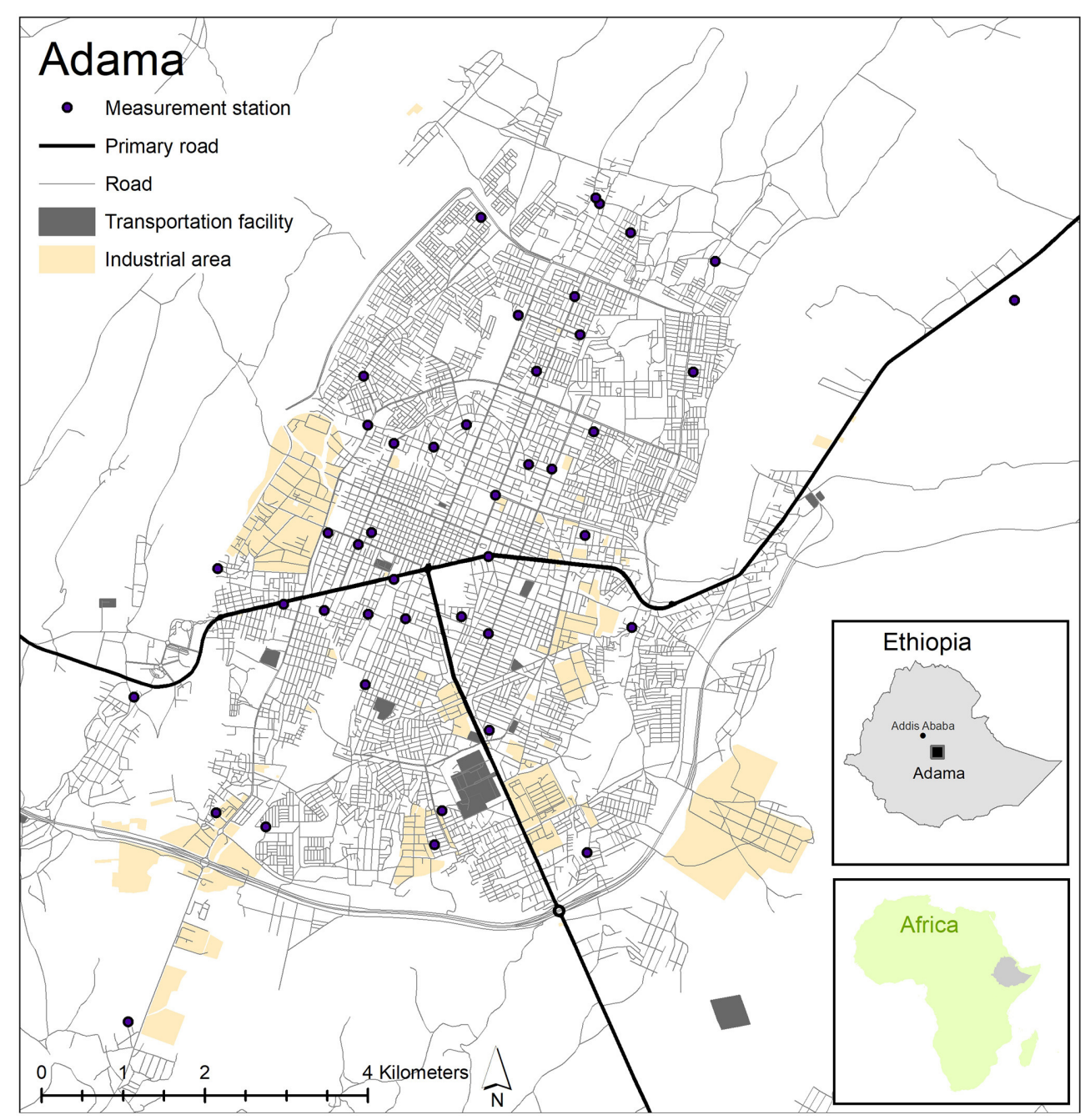

FIGURE 1 | Adama's geographic location in Ethiopia, its location in east Africa, and the measurement stations and key land-use classifications used for modeling $\mathrm{NO}_{2}$ and $\mathrm{NO}_{x}$ (further discussed in Section 2.4 Exposure Assessment).

date has investigated environmental injustice, nor included all of these environmental exposures (ambient air pollution, household air pollution, and urban green space access), in Ethiopia. Including all three illustrates the multitude of environmental exposures humans face simultaneously and captures a more comprehensive picture of environmental injustice's reach. The aim of this study is to explore environmental injustice, specifically the associations between SES and (1) ambient air pollution, (2) household air pollution, and (3) urban green space access, in Adama, Ethiopia.

\section{MATERIALS AND METHODS}

\section{Study Setting}

Adama is the fourth largest city in Ethiopia with an estimated 214,000 inhabitants and is located southeast of the capital, Addis Ababa (see Figure 1). Situated along the Pan African Highway linking the harbor in Djibouti with Addis Ababa, Adama experiences a large amount of freight transport by trucks.
Although a relatively new road has been built outside the city center to divert this heavy transit, it is a toll road, which many drivers choose to avoid. The vehicle fleet in Adama is comprised of cars and trucks that are often old and lack exhaust treatment systems, such as catalytic converters (Brunekreef, 2005; Adama City Administrative Office, 2019). In recent years, polluting rickshaws no longer permitted in Indian cities have been exported to Adama (Adama City Administrative Office, 2019). Additionally, waste is often burned outside homes or in empty lots because formal public waste collection services are not available (Teshome, 2021). Furthermore, many households lack reliable, affordable electricity for cooking, and even when electricity is available, women may continue to use solid fuels to uphold traditional cooking practices (Keil et al., 2010).

\section{Study Population}

The Adama Mother and Child cohort is a prospective cohort (ClinicalTrials.gov identifier number NCT03305991) of 2,085 pregnant women. These women were recruited from three 
public antenatal care clinics (Adama Hospital, Adama Health Centre, and Geda Health Centre) in urban Adama, Ethiopia, from November 2015 to February 2018 (Tesfaye et al., 2020). Women were eligible for participation at the first antenatal care visit for the current pregnancy if they consented to study procedures, including tracing by phone and home visits, and if they were residing in the uptake area for the duration of the pregnancy. At inclusion, interviews and questionnaires were administered to obtain obstetric, health-related, demographic, and socioeconomic data as well as information on cooking practices, such as fuel type(s) used. Physical examinations and blood sampling were also conducted at this time. Later, home visits were performed to collect the GPS coordinates of each woman's residence during pregnancy, additional characteristics of the home, and features of the immediate environment, including urban greenery. This cohort has previously been used to study infectious diseases (König Walles et al., 2018; Tesfaye et al., 2020; Walles et al., 2020). See Supplementary Figure 1 for the flowchart detailing all cases excluded from the study population with respect to environmental exposure data.

\section{Socioeconomic Status Indicators}

Self-reported data on education and occupation was derived from the aforementioned questionnaires. Education had the following categories: illiterate, less than grade 6 , grades $6-12$, or more than grade 12 . These were collapsed into two variables, including one with three categories: "illiterate and $<$ grade 6 " $(n=676)$, "grades 6-12" $(n=1,172)$, and " $>$ grade 12 " $(n$ $=231$ ) and one dichotomized into "low education" (illiterate and $<$ grade $6 ; n=676$ ) and "high education" (grades 6-12 and $>$ grade $12 ; n=1,403$ ). The latter reflects the separation of primary and secondary education in Ethiopia. Occupation alternatives included daily laborer, permanent employment, student, homemaker, unemployed, and self-employed. Here, occupations not comprising paid employment (homemaker, unemployed, and student) were excluded from analysis. The remaining occupations were dichotomized into "daily laborer" ( $n=248)$ and permanent employment and self-employed (hereafter referred to together as "permanent employment"; $n$ $=437)$. As $\sim 63 \%(n=1,319)$ of the women in this study were homemakers, this reduced the sample size for occupation-related analyses substantially.

\section{Exposure Assessment \\ Ambient Air Pollution}

Land-use regression (LUR) models for nitrogen dioxide $\left(\mathrm{NO}_{2}\right)$ and nitrogen oxides $\left(\mathrm{NO}_{\mathrm{x}}\right)$ throughout Adama have been developed previously and published (Abera et al., 2021). These particular air pollutants are commonly used as proxies to capture air pollution exposure generated by combustion. In short, $\mathrm{NO}_{2}$ and $\mathrm{NO}_{\mathrm{x}}$ concentrations were measured at more than 40 sites (Figure 1) over the course of 6 days during both the wet and dry seasons. The measured mean $\mathrm{NO}_{2}$ and $\mathrm{NO}_{\mathrm{x}}$ levels for the entire city were $13.1 \mu \mathrm{g} / \mathrm{m}^{3}$ and $29.0 \mu \mathrm{g} / \mathrm{m}^{3}$, respectively. Traffic measurement sites had the highest $\mathrm{NO}_{2}$ and $\mathrm{NO}_{\mathrm{x}}$ averages of $17.5 \mu \mathrm{g} / \mathrm{m}^{3}$ and $45.0 \mu \mathrm{g} / \mathrm{m}^{3}$, respectively. The lowest mean values were found at the regional background measurement sites: $5.0 \mu \mathrm{g} / \mathrm{m}^{3}$ of $\mathrm{NO}_{2}$ and $11.0 \mu \mathrm{g} / \mathrm{m}^{3}$ of $\mathrm{NO}_{\mathrm{x}}$. The LUR models included geographical predictor variables related to roads, industries $\left(\mathrm{NO}_{2}\right.$ only), and transportation administration areas $\left(\mathrm{NO}_{\mathrm{x}}\right.$ only) (Figure 1). Further details on the full models can be found in Abera et al. (2021). Approximately $75 \%$ of the $\mathrm{NO}_{2}$ variance and $68 \%$ of the $\mathrm{NO}_{\mathrm{x}}$ variance could be explained by the developed LUR models (Abera et al., 2021). In addition to the measurements taken with passive samplers, we were granted access to time-resolved $\mathrm{NO}_{2}$ and $\mathrm{NO}_{\mathrm{x}}$ data collected with a Thermo Scientific NO- $\mathrm{NO}_{2}-\mathrm{NO}_{\mathrm{x}}$ analyzer (model 42i) at the Ethiopian Meteorological Institute site in Adama from January 2017 through December 2018. Although the data had many gaps, air pollution concentrations did not appear to fluctuate considerably between the two years, so no temporal adjustments were made (Abera et al., 2021).

Local personnel, instructed on how to use a handheld Garmin GPS-tracker, were able to collect the geographical coordinates of $1,656(79.4 \%)$ women's home residences during the home visit; others could not be reached $(n=428)$. Women whose geographical coordinates were not correctly recorded $(n=31)$ or fell outside of the area with available geographical predictor data $(n=17)$ were excluded. To preserve a large enough sample size, coordinates that were written as degree, minute, and second $(n=238)$ instead of degree and minute were retained in the main analyses, but a sensitivity analysis excluding them was performed. Information regarding geographical predictor variables included in the LUR models was then extracted from around the home residence of each woman and used to model both $\mathrm{NO}_{\mathrm{x}}$ and $\mathrm{NO}_{2}$ exposure in ArcGIS version 10.5.1 (Redlands, CA, USA). The LUR model predicted one woman's $\mathrm{NO}_{\mathrm{x}}$ exposure to have a negative value, which was subsequently excluded. The resulting modeled mean exposure levels of $\mathrm{NO}_{2}$ and $\mathrm{NO}_{\mathrm{x}}\left(13.7 \mu \mathrm{g} / \mathrm{m}^{3}\right.$ and $29.9 \mu \mathrm{g} / \mathrm{m}^{3}$, respectively), were used to create the final, dichotomized exposure variable: "low exposure" (below the mean) and "high exposure" (above the mean). Additionally, $\mathrm{NO}_{2}$ and $\mathrm{NO}_{\mathrm{x}}$ were dichotomized into emission levels below and above $20 \mu \mathrm{g} / \mathrm{m}^{3}$, which corresponds to the cutoff previously used to study environmental injustice in Sweden (Flanagan et al., 2019).

\section{Household Air Pollution}

Questions regarding the type of fuel(s) that participants used for cooking allowed for multiple answers and included the following options: electricity, gas/kerosene, wood/charcoal, cow dung, cylinders (liquid petroleum gas, LPG), and other. The "other fuel(s)" alternative was excluded from analyses due to a low response rate $(n=1)$. The remaining fuel types were grouped into three categories, "clean fuel" (electricity/gas/kerosene/LPG only; $n=488$ ), "solid fuel" (wood/charcoal/cow dung only; $n=$ 988), and "mixed fuel types" (a combination of clean and solid fuels; $n=593$ ).

Samples of wood, charcoal, and cow dung were collected in Adama, imported to Sweden, and analyzed in the Lund University Aerosol Laboratory (manuscript in preparation). The fuels were burned in a controlled set-up and the chemical composition of the smoke was measured, as were time-resolved mass concentrations, size distributions, and PM collection for 
subsequent analysis. Carbon dioxide $\left(\mathrm{CO}_{2}\right)$ measurements, used to estimate the emitted $\mathrm{PM}_{2.5}$, were measured with a tapered element oscillating microbalance (TEOM) per kg of fuel through carbon mass balance, which facilitated exposure assessment by fuel type. Assumptions for these calculations included the following: four 1-h cooking events (including coffee making) a day; $300 \mathrm{~g}$ of charcoal is used at each event; and the cooking is conducted in a $180 \mathrm{~m}^{3}$ home with an air exchange rate of 15 $\mathrm{h}^{-1}$. This relatively high air exchange rate was chosen because the building envelope of mud houses is highly penetrable due to gaps between the roof and walls and uncovered openings often serving as windows and doors. Additionally, exposure measurements of 28 women's breathing zones during coffee making, all using charcoal, in Adama were conducted using TSI $®$ DustTrak, and the amount of charcoal burned was weighed (Edlund, 2019).

\section{Urban Green Space}

A subjective assessment of the presence of urban green space in the residential area was collected from the women ("yes"; $n$ $=945$ and "no"; $n=668$ ) during the home visit, for which a portion of the study population $(n=428)$ could not be reached. Additional questions on residential characteristics were also asked at this time.

\section{Statistical Analysis}

All analyses were conducted with SPSS Statistical Software

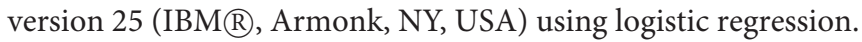
Associations between SES indicators (education and occupation) and ambient air pollution (dichotomous $\mathrm{NO}_{2}$ and $\mathrm{NO}_{\mathrm{x}}$ exposure below/above Adama's mean concentrations and below/above 20 $\mu \mathrm{g} / \mathrm{m}^{3}$ ), household air pollution (fuel type used for cooking), and the presence of green space (yes/no) were investigated and described as odds ratios (ORs) with 95\% confidence intervals (CIs). SES reference categories included "> grade 12," "high education," and "permanent employment."

A sensitivity analysis was conducted pertaining to ambient air pollution, where all women with GPS coordinates written as degree, minute, and second $(n=238)$ instead of degree and minute were excluded.

\section{Ethical Considerations}

Approval for this study was granted by the Ethical Review Board of the Ministry of Science and Technology, Addis Ababa, Ethiopia (310-046-2015) and the Lund University Ethical Committee (Registration numbers: 2015/364 and 2016/576 [amendment]). Written informed consent was obtained from all participants prior to any study procedures. Data was collected and processed strictly under code and stored in a REDCap (www.project-redcap.org) database hosted by the Faculty of Medicine, Lund University, Sweden, to preserve data integrity and maintain study participants' confidentiality.

\section{RESULTS}

Most women in the Adama Mother and Child cohort were between 18 and 29 years old, median 25 years, and virtually all were married ( $\sim 96 \%)$. A slight majority $(\sim 56 \%)$ had completed
TABLE 1 | Demographic information on the women comprising the Adama mother and child cohort $(n=2,085)$ including both household and residential characteristics.

$n$ (\% of total)

\begin{tabular}{|c|c|c|}
\hline \multicolumn{3}{|c|}{ PERSONAL CHARACTERISTICS } \\
\hline \multicolumn{3}{|l|}{ Age } \\
\hline & $<18$ & $19(0.9)$ \\
\hline & $18-24$ & $917(44.0)$ \\
\hline & $25-29$ & $812(38.9)$ \\
\hline & $30-34$ & $256(12.3)$ \\
\hline & $\geq 35$ & 75 (3.6) \\
\hline & Missing & $6(0.3)$ \\
\hline \multicolumn{3}{|c|}{ Marital status } \\
\hline & Single & $64(3.1)$ \\
\hline & Married & 1,994 (95.6 \\
\hline & Divorced & $16(0.8)$ \\
\hline & Widowed & $3(0.1)$ \\
\hline & Missing & $8(0.4)$ \\
\hline
\end{tabular}

Education

$\begin{array}{lc}\text { Illiterate } & 266(12.8) \\ \text { < Grade 6 } & 410(19.7) \\ \text { Grades 6-12 } & 1,172(56.2) \\ \text { > Grade 12 } & 231(11.1) \\ \text { Missing } & 6(0.3)\end{array}$

Occupation

$\begin{array}{lc}\text { Daily laborer } & 248(11.9) \\ \text { Permanent employment } & 274(13.1) \\ \text { Self-employed } & 163(7.8) \\ \text { Homemaker } & 1,319(63.3) \\ \text { Student } & 42(2.0) \\ \text { Unemployed } & 29(1.4) \\ \text { Missing } & 10(0.5)\end{array}$

HOUSEHOLD CHARACTERISTICS

Fuel used for cooking*

$\begin{array}{lc}\text { Electricity } & 1,005(48.2) \\ \text { Gas or kerosene } & 79(3.8) \\ \text { Charcoal or wood } & 1,564(75.0) \\ \text { Animal dung } & 9(0.4) \\ \text { LPG cylinder } & 15(0.7) \\ \text { Other } & 1(0.05) \\ \text { Missing } & 15(0.7)\end{array}$

Electricity

$\begin{array}{lc}\text { Yes } & 1,984(95.2) \\ \text { Missing } & 17(0.8)\end{array}$

Running water

$\begin{array}{lc}\text { Yes } & 1,863(89.4) \\ \text { Missing } & 8(0.4)\end{array}$

Material used for walls

$\begin{array}{lc}\text { Mud } & 751(36.0) \\ \text { Concrete blocks } & 580(27.8) \\ \text { Stone } & 260(12.5) \\ \text { Wood } & 20(1.0) \\ \text { Missing } & 474(22.7)\end{array}$

(Continued) 
TABLE 1 | Continued

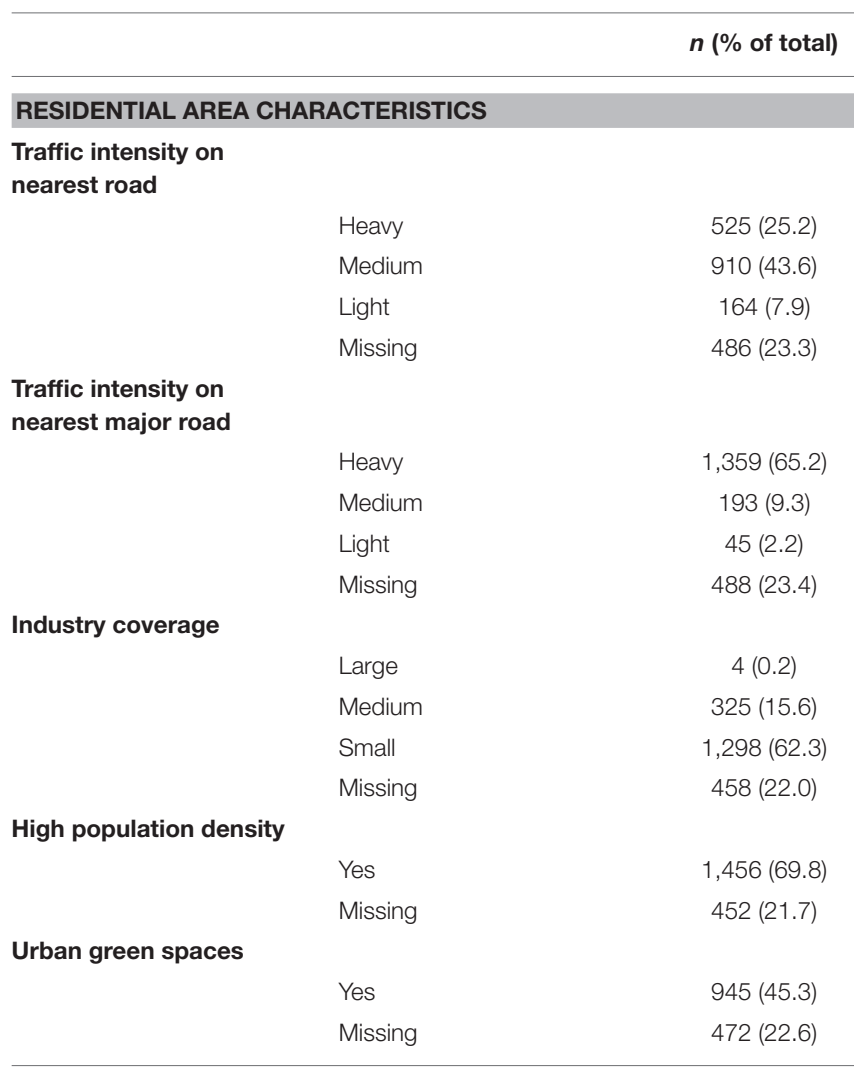

${ }^{\star}$ Participants could select multiple alternatives. LPG, liquid petroleum gas.

schooling between grades 6 through 12, with the most prominent occupation being homemaker $(\sim 63 \%)$. Most households had electricity and running water, and homes were typically built using mud (a mixture of dried soil and organic materials) or concrete blocks. Regarding their residential areas, most women reported heavy to medium traffic nearby but only a small presence of industrial sites. Additionally, the majority of women lived in areas perceived to have a high population density, while $\sim 45 \%$ considered their neighborhood to have green space present. See Table 1 for further details.

\section{Ambient Air Pollution}

Women of the Adama Mother and Child cohort were, on average, exposed to $13.70 \mu \mathrm{g} / \mathrm{m}^{3}$ of $\mathrm{NO}_{2}$ and $29.89 \mu \mathrm{g} / \mathrm{m}^{3}$ of $\mathrm{NO}_{\mathrm{x}}$ (minimum: 4.09 and $0.44 \mu \mathrm{g} / \mathrm{m}^{3}$, maximum: 37.72 and 126.61 $\mu \mathrm{g} / \mathrm{m}^{3}$, respectively). These modeled exposure concentrations, which have been published previously in Abera et al. (2021), are illustrated in Figure 2.

The odds of being exposed to either ambient $\mathrm{NO}_{2}$ or $\mathrm{NO}_{\mathrm{x}}$ concentrations above Adama's mean values steadily increased with decreasing education level (Table 2). When education was dichotomized, this trend continued; however, statistical significance remained only for $\mathrm{NO}_{\mathrm{x}}$. Daily laborers appeared to have slightly higher odds of experiencing greater exposure to $\mathrm{NO}_{2}$ and $\mathrm{NO}_{\mathrm{x}}$, but these results were not statistically significant ( $p=0.35$ and $p=0.39$, respectively). For exposure to $\mathrm{NO}_{2}$ above $20 \mu \mathrm{g} / \mathrm{m}^{3}$ (Table 3), stronger effects were observed for both SES indicators, especially when education was divided into three categories, albeit with wider confidence intervals. The corresponding odds were generally smaller for $\mathrm{NO}_{\mathrm{x}}$ exposure above $20 \mu \mathrm{g} / \mathrm{m}^{3}$ and with greater statistical insignificance. The sensitivity analysis excluding coordinates written as degree, minute, and second produced similar results but with slightly lower ORs (Supplementary Tables 1, 2).

\section{Household Air Pollution}

The likelihood of cooking with solid fuels only as compared to clean fuels only was closely linked to education levels. Women who attended less than grade 6 of schooling and those who attended grades $6-12$ were $\sim 13$ times and 4 times more likely to cook with solid fuels only, respectively, compared to those who attended school past grade 12 (Table 4). When education level was dichotomized, those with primary school education (low education) had about 3.6 times greater odds of using solid fuels only as compared to those who attended secondary school (high education). Concerning occupation, women employed as daily laborers were 5 times more likely to cook with solid fuels only compared to those with permanent employment. Similar trends, though with lower ORs, were seen for the use of solid fuels only vs. a mix of clean and solid fuels. Even when considering the odds of using a combination of clean and solid fuels against clean fuels only, lower SES women tended to have slightly greater odds of using the dirtier option (mixed fuels) than their higher SES counterparts, though some statistical insignificance was present.

Cooking with charcoal generated an estimated indoor 24$\mathrm{h}$ average exposure of $260 \mu \mathrm{g} / \mathrm{m}^{3}$ of $\mathrm{PM}_{2.5}$ in addition to any outdoor exposures. The emission factor obtained for charcoal combustion in a ceramic Mirchaye stove was $3.3 \mathrm{~g} / \mathrm{kg}$ fuel. Wood combustion generated several times higher $\mathrm{PM}_{2.5}$ emissions of varying chemical composition per kg fuel compared to charcoal, and dung gave twice the emissions per $\mathrm{kg}$ compared to wood in our experiments. As a greater amount of fuel is needed per day for wood- and dung-fired cooking compared to charcoal, $\mathrm{PM}_{2.5}$ exposure increases even more: by approximately one order of magnitude (a factor of 10) for wood and twice that for dung, assuming indoor cooking.

\section{Urban Green Space}

Women with an education below grade 6 were nearly 3 times more likely to report a lack of green space around their residency than those with education levels above grade 12, and those who had attended grades 6-12 had double the odds of experiencing a lack of green space compared to the most highly educated women (Table 5). A similar trend remained when education level was dichotomized. Further, those who worked as daily laborers were more than twice as likely to report a lack of green space in their residential area compared to those who had permanent employment.

\section{DISCUSSION}

Environmental injustice was found to be present in Adama, as women of lower socioeconomic status had consistently greater 

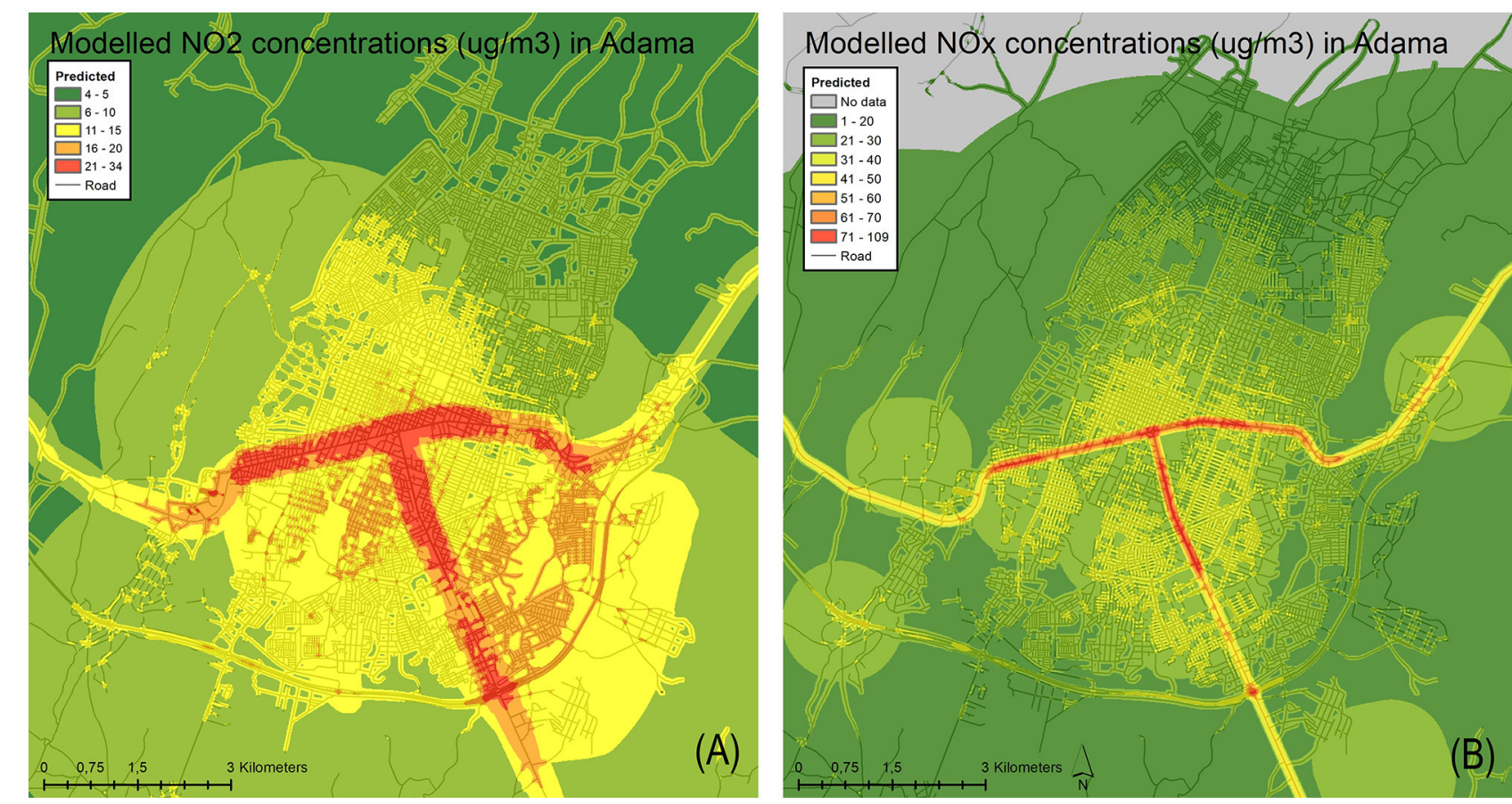

FIGURE 2 | Modeled concentrations of $\mathrm{NO}_{2}$ (left) and $\mathrm{NO}_{x}$ (right), measured in $\mu \mathrm{g} / \mathrm{m}^{3}$, throughout Adama, Ethiopia.

TABLE 2 | Odds of being exposed to levels of $\mathrm{NO}_{2}$ and $\mathrm{NO}_{x}$ above the mean (13.70 and $29.89 \mu \mathrm{g} / \mathrm{m}^{3}$, respectively) associated with education level and occupation among women in the Adama Mother and Child cohort.

\begin{tabular}{|c|c|c|}
\hline \multirow[b]{3}{*}{ Education level } & \multicolumn{2}{|c|}{ OR (95\% Cl) } \\
\hline & $\mathrm{NO}_{2}$ & $\mathrm{NO}_{\mathrm{x}}$ \\
\hline & $N=1,606$ & $N=1,605$ \\
\hline Illiterate and < Grade 6 & $1.71(1.19-2.45)^{\star \star}$ & $2.14(1.49-3.09)^{\star *}$ \\
\hline Grades 6-12 & $1.65(1.17-2.32)^{\star \star}$ & $1.88(1.33-2.67)^{\star \star}$ \\
\hline > Grade 12 & REF & REF \\
\hline Education level ${ }^{a}$ & $N=1,606$ & $N=1,605$ \\
\hline Low & $1.13(0.91-1.40)$ & $1.26(1.02-1.56)^{*}$ \\
\hline High & REF & REF \\
\hline Occupation & $N=540$ & $N=539$ \\
\hline Daily laborer & $1.19(0.83-1.70)$ & $1.17(0.82-1.66)$ \\
\hline Permanent employment & REF & REF \\
\hline
\end{tabular}

Number of included participants $(N)$ is presented.

OR, Odds ratio; Cl, Confidence interval. ${ }^{a}$ Low $=$ Illiterate and $<$ Grade 6, High $=$ Grades 6-12 and $>$ Grade 12. REF, reference category. ${ }^{\star} p \leq 0.05$. ${ }^{\star *} p \leq 0.01$.

odds of being exposed to higher levels of ambient $\mathrm{NO}_{2}$ and $\mathrm{NO}_{\mathrm{x}}$ concentrations, using solid fuels that produce high levels of $\mathrm{PM}_{2.5}$, and living in areas that lack green space. Moreover, odds were stronger for ambient $\mathrm{NO}_{2}$ exposure when using a higher exposure concentration cut-off $\left(20 \mu \mathrm{g} / \mathrm{m}^{3}\right)$, which we
TABLE 3 | Odds of being exposed to levels of $\mathrm{NO}_{2}$ and $\mathrm{NO}_{x}$ above $20 \mu \mathrm{g} / \mathrm{m}^{3}$ associated with education level and occupation among women in the Adama Mother and Child cohort.

\begin{tabular}{lcc}
\hline & \multicolumn{2}{c}{ OR (95\% Cl) } \\
\cline { 2 - 3 } & \multicolumn{1}{c}{$\mathbf{N O}_{\mathbf{2}}$} & $\mathbf{N O}_{\mathbf{x}}$ \\
\cline { 2 - 3 } Education level & $\mathbf{N}=\mathbf{1 , 6 0 6}$ & $\mathbf{N}=\mathbf{1 , 6 0 5}$ \\
\hline Illiterate and $<$ Grade 6 & $5.80(2.77-12.16)^{\star \star}$ & $1.33(0.82-2.14)$ \\
Grades 6-12 & $4.45(2.15-9.24)^{\star \star}$ & $1.71(1.09-2.69)^{\star}$ \\
$>$ Grade 12 & $\mathrm{REF}$ & $\mathrm{REF}$ \\
\hline Education level & $\mathbf{N}=\mathbf{1 , 6 0 6}$ & $\mathbf{N}=\mathbf{1 , 6 0 5}$ \\
\hline Low & $1.53(1.16-2.01)^{\star \star}$ & $0.87(0.62-1.20)$ \\
High & $\mathrm{REF}$ & $\mathrm{REF}$ \\
\hline Occupation & $\mathbf{N}=\mathbf{5 4 0}$ & $\mathbf{N}=\mathbf{5 3 9}$ \\
\hline Daily laborer & $1.61(0.98-2.64)$ & $1.38(0.72-2.64)$ \\
Permanent employment & $\mathrm{REF}$ & $\mathrm{REF}$ \\
\hline
\end{tabular}

Number of included participants $(N)$ is presented.

OR, Odds ratio; Cl, Confidence interval. ${ }^{2}$ Low $=$ Illiterate and $<$ Grade 6, High $=$ Grades 6-12 and $>$ Grade 12. REF, reference category. ${ }^{*} p \leq 0.05 .{ }^{* *} p \leq 0.01$.

have previously used when studying environmental injustice in Sweden (Flanagan et al., 2019), as opposed to Adama's mean $\left(13.7 \mu \mathrm{g} / \mathrm{m}^{3}\right)$, illustrating lower SES persons' increasing risk of exposure to even higher levels of air pollution. These results are also in line with the few environmental injustice studies 
TABLE 4 | Odds of using solid fuels for cooking associated with education level and occupation among women in the Adama Mother and Child cohort.

\begin{tabular}{|c|c|c|c|}
\hline \multirow[b]{3}{*}{ Education level } & \multicolumn{3}{|c|}{ OR (95\% Cl) } \\
\hline & $\begin{array}{l}\text { Solid vs. clean } \\
\text { fuels }\end{array}$ & $\begin{array}{l}\text { Solid vs. } \\
\text { mixed fuels }\end{array}$ & $\begin{array}{l}\text { Mixed vs. } \\
\text { clean fuels }\end{array}$ \\
\hline & $N=1,476$ & $N=1,581$ & $N=1,081$ \\
\hline $\begin{array}{l}\text { Illiterate and < } \\
\text { Grade } 6\end{array}$ & $\begin{array}{c}12.88 \\
(8.30-19.98)^{\star \star}\end{array}$ & $\begin{array}{c}7.04 \\
(4.63-10.72)^{\star \star}\end{array}$ & $\begin{array}{c}1.83 \\
(1.24-2.69)^{\star \star}\end{array}$ \\
\hline Grades 6-12 & $\begin{array}{c}4.49 \\
(3.01-6.69)^{\star *}\end{array}$ & $\begin{array}{c}3.70 \\
(2.48-5.52)^{\star \star}\end{array}$ & $\begin{array}{c}1.21 \\
(0.88-1.67)\end{array}$ \\
\hline > Grade 12 & REF & REF & REF \\
\hline Education level $l^{a}$ & $N=1,476$ & $N=1,581$ & $N=1,081$ \\
\hline Low & $\begin{array}{c}3.55 \\
(2.73-4.62)^{\star *}\end{array}$ & $\begin{array}{c}2.26 \\
(1.80-2.82)^{\star \star}\end{array}$ & $\begin{array}{c}1.58 \\
(1.17-2.12)^{\star \star}\end{array}$ \\
\hline High & REF & REF & REF \\
\hline Occupation & $N=486$ & $N=507$ & $N=367$ \\
\hline Daily laborer & $\begin{array}{c}5.31 \\
(3.39-8.30)^{\star *}\end{array}$ & $\begin{array}{c}3.73 \\
(2.50-5.55)^{\star \star}\end{array}$ & $\begin{array}{c}1.42 \\
(0.86-2.37)\end{array}$ \\
\hline $\begin{array}{l}\text { Permanent } \\
\text { employment }\end{array}$ & REF & REF & REF \\
\hline
\end{tabular}

Number of included participants $(N)$ is presented.

OR, Odds ratio; $\mathrm{Cl}$, Confidence interval. Solid fuels = wood/charcoal/cow dung only. Clean fuels = electricity/gas/kerosene/liquid petroleum gas cylinder only. Mixed fuels = a combination of clean and solid fuels. ${ }^{a}$ Low $=$ Illiterate and $<$ Grade 6, High $=$ Grades $6-12$ and $>$ Grade 12. REF, reference category. ${ }^{*} p \leq 0.05 .{ }^{* *} p \leq 0.01$.

conducted in Sub-Saharan Africa. In Accra, Ghana, for instance, higher SES areas were associated with lower concentrations of $\mathrm{PM}_{2.5}$ and $\mathrm{PM}_{10}$ (Rooney et al., 2012). Considering urban green areas in Nakuru, Nigeria, dissatisfaction with available green spaces rose in a stepwise manner as SES decreased (Ochodo et al., 2014). This is parallel to our results of the reported lack of green space in women's residential areas increasing incrementally as education decreased and being more likely among daily laborers compared to those with permanent employment. Thus, any investigation and mitigation efforts concerning environmental exposures Sub-Saharan African cities should not assume equal exposures across the population, but rather consider the complex and nuanced exposure gradients that exist in relation to socioeconomic status.

\section{Ambient Air Pollution}

The regulation and governance of air pollution has proven to be an immense challenge in LICs and LMICs, particularly in Sub-Saharan Africa (Amegah and Agyei-Mensah, 2017; Makoni, 2020; Mir Alvarez et al., 2020). For instance, a study found that most African countries have not incorporated the World Health Organization's (WHO) air pollution guidelines into their national legislations, and $45 \%$ of African countries did not have any air pollution regulations whatsoever (Joss et al., 2017). In Ethiopia, proclamation No. 300/2002 on "Environmental Pollution Control” specifies standards for ambient air quality,
TABLE 5 | Odds of experiencing a lack of green space in the residential area associated with education level and occupation among women in the Adama Mother and Child cohort.

\begin{tabular}{|c|c|}
\hline \multirow[b]{3}{*}{ Education level } & OR $(95 \% \mathrm{Cl})$ \\
\hline & Lack of green space \\
\hline & $N=1,610$ \\
\hline Illiterate and < Grade 6 & $2.93(2.02-4.25)^{\star \star}$ \\
\hline Grades 6-12 & $2.06(1.44-2.94)^{\star \star}$ \\
\hline > Grade 12 & REF \\
\hline Education level ${ }^{a}$ & $N=1,610$ \\
\hline Low & $1.59(1.29-1.97)^{\star \star}$ \\
\hline High & REF \\
\hline Occupation & $N=540$ \\
\hline Daily laborer & $2.27(1.58-3.25)^{\star \star}$ \\
\hline Permanent employment & REF \\
\hline
\end{tabular}

Number of included participants $(N)$ is presented.

OR, Odds ratio; $\mathrm{Cl}$, Confidence interval. ${ }^{a} \mathrm{Low}=$ Illiterate and $<$ Grade 6, High $=$ Grades 6-12 and $>$ Grade 12. REF, reference category. ${ }^{*} p \leq 0.05 .{ }^{* *} p \leq 0.01$.

yet no documents outlining national or regional strategies to translate these policies into practice exist (Mitike et al., 2016). As a result, there are inadequate implementation processes to encourage adherence and manage enforcement (Mitike et al., 2016). While air quality control may be sparse, mean modeled $\mathrm{NO}_{2}$ exposure levels in Adama $\left(13.70 \mu \mathrm{g} / \mathrm{m}^{3}\right)$ appeared to fall well below the current WHO and European Union air quality guideline of $40 \mu \mathrm{g} / \mathrm{m}^{3}$ (annual average) (EU, 2008; World Health Organization, 2018). Still, the maximum $\mathrm{NO}_{2}$ exposure levels modeled in Adama $\left(37.72 \mu \mathrm{g} / \mathrm{m}^{3}\right)$ approach this limit, which is currently under revision by WHO and is likely to be lowered (World Health Organization, 2018).

\section{Household Air Pollution}

As women in Adama with lower education and daily laborer employment had consistently greater odds of cooking with pollutive solid fuels, the case for prioritizing women of lower SES for initiatives involving cleaner fuel supplementation and subsidization is strong. Further, charcoal was found to generate 24-h average exposure levels of $\mathrm{PM}_{2.5}$ that exceeded the WHO's indoor exposure guideline $\left(25 \mu \mathrm{g} / \mathrm{m}^{3}\right.$ ) (World Health Organization, 2010) by a factor of 10 . Still, this fuel type was the least polluting of the three studied, and cow dung, the cheapest fuel, was the most polluting. This illustrates that providing people in low-income countries the possibility of substituting their energy source, even with respect to solid fuels, could contribute to a relative improvement in indoor air quality. On the other hand, charcoal production itself leads to emissions elsewhere, and the substitution of solid fuels with gas or electricity is a more sustainable alternative.

While significant efforts have been made to curb household air pollution from cook stoves (Pilishvili et al., 2016; Puzzolo 
et al., 2016; Yip et al., 2017), not all interventions have been effective (Tsephel et al., 2009; Eshetu, 2014; Sanbata et al., 2014; Quansah et al., 2017; Jürisoo et al., 2018). An alternative to the traditional approach of stand-alone, household-scale delivery of products is the utility-scale service model (Ray and Smith, 2021). This may include reliable electricity from regulated minigrids or cost-efficient distribution of liquefied petroleum gas (LPG) (Ray and Smith, 2021). The former is applicable to our study setting, where $\sim 95 \%$ of women have electricity in their household but still use solid fuels (74\%)- often due to electricity being more expensive and/or not in continuous supply (Kapsalyamova et al., 2021). Further, supplying households in India and the Kyrgyz Republic with gas, particularly LPG, reduced solid fuel use (Kapsalyamova et al., 2021). A similar utility transition is a promising option for Adama, where the use of gas, kerosene or LPG is low (4.5\%). While the need for individual behavior change is acknowledged, people's ability to choose is often constrained by their circumstances (Ray and Smith, 2021). If universal access and uptake of cleaner energy is the goal, services should be planned and delivered such that the health-promoting option becomes the default (Ray and Smith, 2021). State investment in clean, domestic energy services would require the historical inefficiencies, corruption, and poor governance of energy production and delivery to be addressed (Ray and Smith, 2021). With this, the utility-scale service model underscores the importance of political will and government action for large-scale, longterm improvement in indoor air quality (Ray and Smith, 2021).

\section{Urban Green Space}

Most research on urban green space has been conducted in higher-income countries (Rupprecht and Byrne, 2014; Kabisch et al., 2015), but this has recently expanded to include lower-income countries in Sub-Saharan Africa (Chamberlain et al., 2019; Vancampfort et al., 2019; Sardeshpande and Shackleton, 2020; Yessoufou et al., 2020). Of particular interest is urbanization, which drives a rapid shift in land-use, including the removal of natural vegetation and the construction of housing, infrastructure, and industry. These coalesce to drive land surface temperature increases, as demonstrated in urban Nigeria (Fashae et al., 2020) and the Ethiopian highlands (Yohannes et al., 2020). In Ethiopia's capital city Addis Ababa, green spaces, including urban forest and urban agriculture, have undergone a rapid decline (Teferi and Abraha, 2017; Azagew and Worku, 2020), and only $0.37 \mathrm{~m}^{2}$ of park space per capita is available to residents (Azagew and Worku, 2020). Indeed, the reduction of overall vegetation cover in Addis Ababa and the reported $\sim 16 \%$ increase in built-up area from 1985 to 2015 is considered to have contributed to the land surface temperature of the city increasing $3-8^{\circ} \mathrm{C}$ over the same time period (Worku et al., 2021). Adama, on the other hand, has $2.1 \mathrm{~m}^{2}$ of park space per capita (Azagew and Worku, 2020), but this still falls short of the standards provided by the WHO $\left(9 \mathrm{~m}^{2}\right.$ ) (World Health Organization, 2016c) and the Ethiopian Urban Green Infrastructure Standard $\left(15 \mathrm{~m}^{2}\right.$ ) (Ministry of Urban Development Housing, 2015). Despite master plans with the intention of protecting, expanding, or creating new urban green spaces, such objectives rarely become reality in most Ethiopian cities due to low enforcement of development plans, pressured expansion of built-up areas, weak prioritization of urban green spaces, financial constraints, lack of professional knowledge, and insufficient public involvement (Girma et al., 2019; Azagew and Worku, 2020). Fortunately, it appears that a greater understanding of the positive benefits of urban vegetation and green space is emerging (Herslund et al., 2018). Protecting and expanding these spaces remains one of the most promising climate change adaptations strategies that can help reduce the urban heat island effect and improve human health (Teferi and Abraha, 2017).

\section{A Societal and Human Rights Approach}

From a societal perspective, the present results underline the importance of educational and occupational opportunities. These upstream determinants, rather than policy regulations or technical solutions, offer an additional pathway through which individual risk of air pollution exposure can be reduced and access to urban green space can be improved (Ahlers, 2016). Furthermore, higher educational attainment can contribute to greater awareness of environmental exposures. Several studies conducted in Sub-Saharan Africa have noted awareness of air pollution exposure and its health effects to rise as education increased (Egondi et al., 2013; Omanga et al., 2014; Nwankwo et al., 2018; Odonkor and Mahami, 2020). Such awareness is essential to promote individual behavioral change (Muindi et al., 2014; Nwankwo et al., 2018), stimulate grassroots engagement, and generate public demand for policy creation. Addressing these environmental exposures, however, requires governmental action (Ngo et al., 2015; Breathelife, 2016; Bahino et al., 2018). Utilizing a human rights perspective would provide governments with clear, legally enforceable obligations to act, as ambient and household air pollution and dwindling urban green space violates the right to good health (Boyd, 2019). Indeed, Ethiopia's own constitution recognizes access to clean and healthy environments as a fundamental right for which the government is responsible (Article 44/1 Proclamation No. 1/1995). This protection is especially necessary for those disproportionately exposed.

\section{Methodological Considerations}

A key strength of this study is the LUR models developed specifically for assessing ambient air pollution exposure in Adama, which successfully capture the spatial variability of $\mathrm{NO}_{2}$ and $\mathrm{NO}_{\mathrm{x}}$ (Abera et al., 2021). Additionally, the aerosol chamber analysis of cooking fuel samples taken directly from the study area increase the reliability of our inferences regarding household air pollution exposure. The Adama Mother and Child cohort has been successfully utilized in previous studies, and the geographic location of each woman's home residence was manually collected, which helped reduce the risk of exposure misclassification for those women included in analyses. The use of in-depth questionnaire data for SES ( $<1 \%$ missing) is considered an additional strength, as official registers maintained by governmental agencies are lacking. Furthermore, antenatal care facilities offer a unique opportunity for epidemiological studies, where a representative sample of otherwise healthy 
women can be accessed. Our study population was quite diverse, capturing a range of education levels and occupations, and $\sim 96 \%$ of the households could be characterized by married women expecting a child. We, therefore, believe that this study is representative of, and the results generalizable to, families residing in urban Ethiopia, with the exception of extremes in wealth and poverty. Finally, this is a novel study, as very few studies on environmental injustice in LICs and LMICs have been conducted. To the best of our knowledge, this is also the first study on environmental injustice in Ethiopia and the first in Sub-Saharan Africa to investigate the inequalities of several environmental exposures in the same cohort.

Several limitations are also present. Common to all air pollution epidemiology studies, exposure misclassification is a possible limitation. The use of well-performing LUR models and individual residential addresses can help decrease this bias. Even so, data on some important geographical predictor variables was not available, which is further discussed in Abera et al. (2021). As previously mentioned, a number of residential address coordinates were registered as degree, minute, and second $(n=238)$; these were treated as degree and minute in the main analysis and, thereby, introduced some uncertainty. However, our sensitivity analysis demonstrated that their inclusion did not substantially alter the results (Supplementary Tables 1, 2). Not reaching 428 women for home visits is also a limitation, but these women did not seem to differ greatly in terms of socioeconomic status compared to those who were able to be reached (Supplementary Table 3).

Using cooking fuel type as a proxy for household air pollution may also increase the risk of exposure misclassification (Odo et al., 2021). Nevertheless, the response-rate for fuel type was high, with $<1 \%$ missing. It should be noted that the category "solid fuels" comprises three fuel types whose emissions differ greatly. Charcoal appeared to be the most commonly used fuel in Adama from previous field visits. The estimated exposure from cooking also has its limitations; for instance, the estimations were based on the fuel alone, excluding any additional exposure from the food and cooking oil; all emissions were assumed to mix into the residence volume uniformly and instantaneously; and many homes have a volume smaller than that assumed in the model. This may have led to an underestimation of the true cooking emissions. Still, the exposure concentrations from the laboratory experiments were in line with the calculated 24h average of $262 \mu \mathrm{g} / \mathrm{m}^{3}$ from DustTrak measurements taken in the breathing zone of charcoal-fueled coffee preparation by women in Adama (Edlund, 2019), despite the model being greatly simplified.

Responses regarding the presence of green space were subjective, but such accounts have been suggested to be preferable when evaluating the quality or experience of greenness as opposed to an objective measure of the quantity of green space (Leslie et al., 2010). The reliance on selfreported data for SES indicators and cooking fuel type may have contributed to response bias. Furthermore, the decision to limit occupation-related analyses to only positions with paid employment significantly reduced the sample population, which might have led to decreased power and increased uncertainty for the results concerning this particular SES indicator. Missing data on urban green space $(\sim 23 \%)$ can also be seen as a limitation. There was a slight tendency for women identifying as illiterate to be missing more data on green space compared to the most highly educated ( $>10 \%$ difference); however, the percent missing among the occupation categories studied were relatively similar (Supplementary Table 4).

\section{Future Research}

Future studies, especially health impact assessments, in Ethiopia and other countries in Sub-Saharan Africa investigating environmental exposures and their health effects would benefit from stratifying their analyses by SES. Not doing so could incorrectly homogenize exposures and potentially mask an existing gradient, which would, consequently, derive inaccurate risk assessments. This stratification would also provide insight into practical strategies for policy implementation- demonstrating where interventions are most needed and for whom they would most benefit. Additionally, participatory research methods that directly involve members of the community should be prioritized to further improve awareness and inspire agency; this is important for long-term engagement and to generate momentum for political change (Ngo et al., 2017).

\section{CONCLUSIONS}

We found evidence of environmental injustice in Adama, Ethiopia, as residents with less education and/or employment as daily laborers experienced higher exposure to ambient and household air pollution than their more educated, permanently employed counterparts. These lower SES women were also more likely to lack urban green space in their residential areas. Considering socioeconomic differences in environmental exposures is important to better understand existing exposure gradients and to help identify priority populations for policy planning and applied interventions. From a societal perspective, these results also support investment in educational and occupational opportunities; however, governments are ultimately responsible for the protection of the human right to a clean environment for all.

\section{DATA AVAILABILITY STATEMENT}

The data analyzed in this study is subject to the following licenses/restrictions: The ethical permissions granted for this project outline restrictions that limit dataset access to only those researchers involved in the project, as sensitive information on individual exposure levels of air pollution, socioeconomic status, demographics, and health is present. Requests to access these datasets should be directed to Ebba Malmqvist, ebba.malmqvist@med.lu.se. 


\section{ETHICS STATEMENT}

The studies involving human participants were reviewed and approved by Ethical Review Board of the Ministry of Science and Technology, Addis Ababa, Ethiopia (310-046-2015) and the Lund University Ethical Committee (Registration numbers: 2015/364 and 2016/576 [amendment]). Written informed consent to participate in this study was provided by the participants; if the participant was a minor, their legal guardian/next of kin provided written informed consent.

\section{AUTHOR CONTRIBUTIONS}

CI and EM were responsible for the conceptualization of this study and funding acquisition. EM was responsible for project administration. Data curation was performed by JW, CI, KM, AA, EM, and AE. Preliminary investigations were conducted by JW, CI, KM, AA, EM, AE, and FB. Formal analysis was performed by EF, AO, and EM. EF wrote the original draft of the manuscript. All authors aided in manuscript revision, read, and approved the submitted version.

\section{REFERENCES}

Abera, A., Malmqvist, E., Mandakh, Y., Flanagan, E., Jerrett, M., Gebrie, G. S., et al. (2021). Measurements of NOx and development of land use regression models in an East-African City. Atmosphere 12:519. doi: 10.3390/atmos120 40519

Adama City Administrative Office (2019). Adama City Administrative Office Report.

Ahlers, C. D. (2016). Race, ethnicity, and air pollution: new directions in environmental justice. J. Environ. Law 2016, 713-758. Available online at: http://www.jstor.org/stable/44272868

Amegah, A. K., and Agyei-Mensah, S. (2017). Urban air pollution in Sub-Saharan Africa: time for action. J. Environ. Pollut. 220, 738-743. doi: 10.1016/j.envpol.2016.09.042

Azagew, S., and Worku, H. (2020). Accessibility of urban green infrastructure in Addis-Ababa city, Ethiopia: current status and future challenge. Environ. Syst. Res. 9:26. doi: 10.1186/s40068-020-00187-0

Bahino, J., Yoboué, V., Galy-Lacaux, C., Adon, M., Akpo, A., Keita, S., et al. (2018). A pilot study of gaseous pollutants' measurement ( $\mathrm{NO} 2, \mathrm{SO} 2, \mathrm{NH}$ 3, HNO 3 and $\mathrm{O} 3$ ) in Abidjan, Côte d'Ivoire: contribution to an overview of gaseous pollution in African cities. Atmos. Chem. Phys. 18, 5173-5198. doi: 10.5194/acp-18-5173-2018

Balmes, J. R. (2019). Household air pollution from domestic combustion of solid fuels and health. J. Allergy Clin. Immunol. 143, 1979-1987. doi: 10.1016/j.jaci.2019.04.016

Bo, M., Salizzoni, P., Clerico, M., and Buccolieri, R. (2017). Assessment of indoor-outdoor particulate matter air pollution: a review. Atmosphere 8:136. doi: $10.3390 /$ atmos 8080136

Boyd, D. R. (2019). The human right to breathe clean air. Ann. Global Health. 85:146. doi: 10.5334/aogh.2646

Breathelife (2016). A Global Campaign for Clean Air: World Health Organization, Climate \& Clean Air Coalition, UN Environment Programme. World Bank.

Brunekreef, B. (2005). Out of Africa. J. Occup. Environ. Med. 62, 351-352. doi: 10.1136/oem.2005.019927

Carey, I. M., Anderson, H. R., Atkinson, R. W., Beevers, S. D., Cook, D. G., Strachan, D. P., et al. (2018). Are noise and air pollution related to the incidence of dementia? A cohort study in London, England. BMJ Open. 8:e022404. doi: 10.1136/bmjopen-2018-022404

Castro, A., Künzli, N., and Götschi, T. (2017). Health benefits of a reduction of PM10 and NO2 exposure after implementing a clean air plan in the

\section{FUNDING}

This project has received funding from Swedish Research Council Grant No. 2016-05677. Lund University has provided funding for open access publication fees.

\section{ACKNOWLEDGMENTS}

We would like to thank our colleague, Ralf Rittner, for his help with data processing. We would also like to acknowledge Per Björkman, Niclas Winqvist, and all those at the Lund University Adama Research Center for their work on data collection and data management. We are grateful to the Swedish Research Council for providing funding (Grant No. 2016-05677) for this project.

\section{SUPPLEMENTARY MATERIAL}

The Supplementary Material for this article can be found online at: https://www.frontiersin.org/articles/10.3389/frsc.2021. 728384/full\#supplementary-material

Agglomeration Lausanne-Morges. Int. J. Hyg. Environ. Health. 220, 829-839. doi: 10.1016/j.ijheh.2017.03.012

Chakraborty, J., and Basu, P. (2021). Air quality and environmental injustice in India: connecting particulate pollution to social disadvantages. Int. J. Environ. Res. Public Health. 18:304. doi: 10.3390/ijerph180 10304

Chamberlain, D. E., Henry, D. A. W., Reynolds, C., Caprio, E., and Amar, A. (2019). The relationship between wealth and biodiversity: A test of the Luxury Effect on bird species richness in the developing world. Glob. Chang. Biol. 25, 3045-3055. doi: 10.1111/gcb.14682

Chen, J., and Hoek, G. (2020). Long-term exposure to PM and all-cause and cause-specific mortality: A systematic review and meta-analysis. Environ. Int. 143:105974. doi: 10.1016/j.envint.2020.105974

Chun, H., Leung, C., Wen, S. W., McDonald, J., and Shin, H. H. (2020). Maternal exposure to air pollution and risk of autism in children: A systematic review and meta-analysis. Environ. Pollut. 256:113307. doi: 10.1016/j.envpol.2019.113307

Edlund, J. (2019). Air Pollution Emitted During Traditional Coffee Ceremonies in Ethiopia, A Health Risk for Women [MVEM13 Master's Thesis in Environmental Health]. Lund: Lund University.

Egondi, T., Kyobutungi, C., Ng, N., Muindi, K., Oti, S., van de Vijver, S., et al. (2013). Community perceptions of air pollution and related health risks in Nairobi slums. Int. J. Environ. Res. Public Health. 10, 4851-4868. doi: 10.3390/ijerph10104851

Embiale, A., Zewge, F., Chandravanshi, B. S., and Sahle-Demessie, E. (2019). Levels of trace elements in $\mathrm{PM}(10)$ collected at roadsides of Addis Ababa, Ethiopia, and exposure risk assessment. Environ. Monit. Assess. 191:397. doi: 10.1007/s10661-019-7503-3

Eshetu, A. A. (2014). Factors affecting the adoption of fuel efficient stoves among rural households in Borena Woreda: North central Ethiopia. Int. J. Energy Sci. 4, 141-154. doi: 10.14355/ijes.2014.0405.01

EU (2008). Directive 2008/50/EC of the European Parliament and of the Council of 21 May 2008 on ambient air quality and cleaner air for Europe. Offi. J. Eur. Union 1, 1-44. Available online at: http://data.europa.eu/eli/dir/2008/50/oj

Fashae, O. A., Adagbasa, E. G., Olusola, A. O., and Obateru, R. O. (2020). Land use/land cover change and land surface temperature of Ibadan and environs, Nigeria. Environ. Monit. Assess. 192:109. doi: 10.1007/s10661-019-8054-3

Flanagan, E., Stroh, E., Oudin, A., and Malmqvist, E. (2019). Connecting air pollution exposure to socioeconomic status: a cross-sectional study on environmental injustice among pregnant women in scania, Sweden. Int. J. Environ. Res. Public Health. 16:5116. doi: 10.3390/ijerph16245116 
Girma, Y., Terefe, H., Pauleit, S., and Kindu, M. (2019). Urban green infrastructure planning in Ethiopia: The case of emerging towns of Oromia special zone surrounding Finfinne. J. Urban Manage. 8, 75-88. doi: 10.1016/j.jum.2018.09.004

Güneralp, B., Lwasa, S., Masundire, H., Parnell, S., and Seto, K. C. (2017). Urbanization in Africa: challenges and opportunities for conservation. Environ. Res. Lett. 13:015002. doi: 10.1088/1748-9326/aa94fe

Hajat, A., Hsia, C., and O’Neill, M. S. (2015). Socioeconomic disparities and air pollution exposure: a global review. Curr. Environ. Health Rep. 2, 440-450. doi: 10.1007/s40572-015-0069-5

Herslund, L., Backhaus, A., Fryd, O., Jørgensen, G., Jensen, M. B., Limbumba, T. M., et al. (2018). Conditions and opportunities for green infrastructure - Aiming for green, water-resilient cities in Addis Ababa and Dar es Salaam. Landsc. Urban Plan. 180, 319-327. doi: 10.1016/j.landurbplan.2016. 10.008

Hill, A., Hühner, T., Kreibich, V., and Lindner, C. (2014). Dar es Salaam, Megacity of Tomorrow: Informal Urban Expansion and the Provision of Technical Infrastructure. Megacities: Springer. doi: 10.1007/978-90-481-34 17-5_12

Hitchcock, G., Conlan, B., Kay, D., Brannigan, C., and Newman, D. (2014). Air Quality and Road Transport: Impacts and Solutions. London: RAC Foundation.

Hoek, G., Krishnan, R. M., Beelen, R., Peters, A., Ostro, B., Brunekreef, B., et al. (2013). Long-term air pollution exposure and cardio- respiratory mortality: a review. Environ. Health. 12:43. doi: 10.1186/1476-069X-12-43

Hsu, W. T., Liu, M. C., Hung, P. C., Chang, S. H., and Chang, M. B. (2016). PAH emissions from coal combustion and waste incineration. J. Hazard. Mater. 318, 32-40. doi: 10.1016/j.jhazmat.2016.06.038

Huangfu, P., and Atkinson, R. (2020). Long-term exposure to NO2 and $\mathrm{O} 3$ and all-cause and respiratory mortality: A systematic review and meta-analysis. Environ. Int. 144:105998. doi: 10.1016/j.envint.2020. 105998

Joss, M. K., Eeftens, M., Gintowt, E., Kappeler, R., and Künzli, N. (2017). Time to harmonize national ambient air quality standards. Int. J. Public Health 62, 453-462. doi: 10.1007/s00038-017-0952-y

Jürisoo, M., Lambe, F., and Osborne, M. (2018). Beyond buying: The application of service design methodology to understand adoption of clean cookstoves in Kenya and Zambia. Energy Res. Soc. Sci. 39, 164-176. doi: 10.1016/j.erss.2017.11.023

Kabisch, N., Qureshi, S., and Haase, D. (2015). Human-environment interactions in urban green spaces - A systematic review of contemporary issues and prospects for future research. Environ. Impact Assess. Rev. 50, 25-34. doi: 10.1016/j.eiar.2014.08.007

Kapsalyamova, Z., Mishra, R., Kerimray, A., Karymshakov, K., and Azhgaliyeva, D. (2021). Why energy access is not enough for choosing clean cooking fuels? Evidence from the multinomial logit model. J. Environ. Manage. 290:112539. doi: 10.1016/j.jenvman.2021.112539

Keil, C., Kassa, H., Brown, A., Kumie, A., and Tefera, W. (2010). Inhalation exposures to particulate matter and carbon monoxide during Ethiopian coffee ceremonies in Addis Ababa: a pilot study. Int. J. Environ. Res. Public Health 2010:213960. doi: 10.1155/2010/213960

Khreis, H., Kelly, C., Tate, J., Parslow, R., Lucas, K., and Nieuwenhuijsen, M. (2017). Exposure to traffic-related air pollution and risk of development of childhood asthma: A systematic review and meta-analysis. Environ. Int. 100, 1-31. doi: 10.1016/j.envint.2016.11.012

König Walles, J., Tesfaye, F., Jansson, M., Tolera Balcha, T., Winqvist, N., Kefeni, M., et al. (2018). Performance of QuantiFERON-TB Gold Plus for detection of latent tuberculosis infection in pregnant women living in a tuberculosis- and HIV-endemic setting. PLOS ONE 13:e193589. doi: 10.1371/journal.pone.0193589

Landrigan, P. J., Fuller, R., Acosta, N. J., Adeyi, O., Arnold, R., Baldé, A. B., et al. (2017). The Lancet Commission on pollution and health. Lancet. 391, 462-512. doi: 10.1016/S0140-6736(17)32345-0

Lee, A. C., and Maheswaran, R. (2011). The health benefits of urban green spaces: a review of the evidence. J. Public Health 33, 212-222. doi: 10.1093/pubmed/fdq068

Lelieveld, J., Evans, J. S., Fnais, M., Giannadaki, D., and Pozzer, A. (2015). The contribution of outdoor air pollution sources to premature mortality on a global scale. Nature. 525:367-371. doi: 10.1038/nature15371
Leslie, E., Sugiyama, T., Ierodiaconou, D., and Kremer, P. (2010). Perceived and objectively measured greenness of neighbourhoods: Are they measuring the same thing? Landsc. Urban Plan. 95, 28-33. doi: 10.1016/j.landurbplan.2009.11.002

Li, X., Ma, Y., Zhang, M., Zhan, M., Wang, P., Lin, X., et al. (2019). Study on the relationship between waste classification, combustion condition and dioxin emission from waste incineration. Waste Disposal Sustaina. Energy 1, 91-98. doi: 10.1007/s42768-019-00009-9

Makoni, M. (2020). Air pollution in Africa. Lancet Respir. Med. 8:e60-e1. doi: 10.1016/S2213-2600(20)30275-7

Mead, M., Khan, M., White, I., Nickless, G., and Shallcross, D. (2008). Methyl halide emission estimates from domestic biomass burning in Africa. Atmos. Environ. 42, 5241-5250. doi: 10.1016/j.atmosenv.2008.02.066

Ministry of Urban Development and Housing (2015). Ethiopian National Urban Green Infrastructure Standards. Addis Ababa.

Mir Alvarez, C., Hourcade, R., Lefebvre, B., and Pilot, E. (2020). A Scoping review on air quality monitoring, policy and health in West African Cities. Int. J. Environ. Res. Public Health. 17:9151. doi: 10.3390/ijerph17239151

Mitike, G., Motbainor, A., Kumie, A., Samet, J., and Wipfli, H. (2016). Review of policy, regulatory, and organizational frameworks of environment and health in Ethiopia. Ethiop. J. Health Dev. 30, 42-49.

Mocumbi, A. O., Stewart, S., Patel, S., and Al-Delaimy, W. K. (2019). Cardiovascular effects of indoor air pollution from solid fuel: relevance to Sub-Saharan Africa. Curr. Environ. Health Rep. 6, 116-126. doi: 10.1007/s40572-019-00234-8

Mohajerani, A., Bakaric, J., and Jeffrey-Bailey, T. (2017). The urban heat island effect, its causes, and mitigation, with reference to the thermal properties of asphalt concrete. J. Environ. Manage. 197, 522-538. doi: 10.1016/j.jenvman.2017.03.095

Morawska, L., Afshari, A., Bae, G. N., Buonanno, G., Chao, C. Y. H., Hänninen, O., et al. (2013). Indoor aerosols: from personal exposure to risk assessment. Indoor Air. 23, 462-487. doi: 10.1111/ina.12044

Muindi, K., Egondi, T., Kimani-Murage, E., Rocklov, J., and Ng, N. (2014). "We are used to this": a qualitative assessment of the perceptions of and attitudes towards air pollution amongst slum residents in Nairobi. BMC Public Health 14:226. doi: 10.1186/1471-2458-14-226

Naidja, L., Ali-Khodja, H., and Khardi, S. (2018). Sources and levels of particulate matter in North African and Sub-Saharan cities: a literature review. Environ. Sci. Pollut. Res. 25, 12303-12328. doi: 10.1007/s11356-018-1 $715-\mathrm{x}$

Ngo, N., Kokoyo, S., and Klopp, J. (2017). Why participation matters for air quality studies: risk perceptions, understandings of air pollution and mobilization in a poor neighborhood in Nairobi, Kenya. Public Health 142, 177-185. doi: 10.1016/j.puhe.2015.07.014

Ngo, N. S., Gatari, M., Yan, B., Chillrud, S. N., Bouhamam, K., and Kinney, P. L. (2015). Occupational exposure to roadway emissions and inside informal settlements in sub-Saharan Africa: A pilot study in Nairobi, Kenya. Atmos. Environ. 111, 179-184. doi: 10.1016/j.atmosenv.2015.04.008

Niu, Z., Liu, F., Yu, H., Wu, S., and Xiang, H. (2021). Association between exposure to ambient air pollution and hospital admission, incidence, and mortality of stroke: an updated systematic review and meta-analysis of more than 23 million participants. Environ. Health Prev. Med. 26:15. doi: 10.1186/s12199-021-00937-1

Nwankwo, O. N., Mokogwu, N., Agboghoroma, O., Ahmed, F. O., and Mortimer, K. (2018). Knowledge, attitudes and beliefs about the health hazards of biomass smoke exposure amongst commercial food vendors in Nigeria. PLoS ONE. 13:e0191458. doi: 10.1371/journal.pone.01 91458

Ochodo, C., Ndetei, D., Moturi, W., and Otieno, J. (2014). External built residential environment characteristics that affect mental health of adults. J. Urban Health 91, 908-927. doi: 10.1007/s11524-013-9852-5

Odo, D. B., Yang, I. A., and Knibbs, L. D. (2021). A systematic review and appraisal of epidemiological studies on household fuel use and its health effects using demographic and health surveys. Int. J. Environ. Res. Public Health. 18:1411. doi: 10.3390/ijerph18041411

Odonkor, S. T., and Mahami, T. (2020). Knowledge, attitudes, and perceptions of air pollution in Accra, Ghana: a critical survey. J. Environ. Public Health. 2020:3657161. doi: 10.1155/2020/3657161 
Ofori, B. Y., Garshong, R. A., Gbogbo, F., Owusu, E. H., and Attuquayefio, D. K. (2018). Urban green area provides refuge for native small mammal biodiversity in a rapidly expanding city in Ghana. Environ. Monit. Assess. 190:480. doi: 10.1007/s10661-018-6858-1

Okello, G., Devereux, G., and Semple, S. (2018). Women and girls in resource poor countries experience much greater exposure to household air pollutants than men: Results from Uganda and Ethiopia. Environ. Int. 119, 429-437. doi: 10.1016/j.envint.2018.07.002

Omanga, E., Ulmer, L., Berhane, Z., and Gatari, M. (2014). Industrial air pollution in rural Kenya: community awareness, risk perception and associations between risk variables. BMC Public Health. 14:377. doi: 10.1186/1471-2458-14-377

O’Neill, M. S., Jerrett, M., Kawachi, I., Levy, J. I., Cohen, A. J., Gouveia, N., et al. (2003). Health, wealth, and air pollution: advancing theory and methods. Environ. Health Perspect. 111, 1861-1870. doi: 10.1289/ehp.6334

Owili, P. O., Lien, W.-H., Muga, M. A., and Lin, T.-H. (2017). The associations between types of ambient PM2. 5 and Under-five and maternal mortality in Africa. Inter. J. Environ. Res. Public Health 14:359. doi: 10.3390/ijerph14040359

Panyacosit, L. (2000). A Review of Particulate Matter and Health: Focus on Developing Countries. Laxenburg: International Institute for Applied Systems Analysis. doi: 10.2139/ssrn.235099

Pedersen, M., Stayner, L., Slama, R., Sørensen, M., Figueras, F., Nieuwenhuijsen, M. J., et al. (2014). Ambient air pollution and pregnancy-induced hypertensive disorders. Hypertension. 64, 494-500. doi: 10.1161/HYPERTENSIONAHA.114.03545

Perera, F., Ashrafi, A., Kinney, P., and Mills, D. (2019). Towards a fuller assessment of benefits to children's health of reducing air pollution and mitigating climate change due to fossil fuel combustion. Environ. Res. 172, 55-72. doi: 10.1016/j.envres.2018.12.016

Pieterse, E., Parnell, S., and Haysom, G. (2015). Towards an African Urban Agenda. Nairobi: Economic Commission for Africa.

Pilishvili, T., Loo, J. D., Schrag, S., Stanistreet, D., Christensen, B., Yip, F., et al. (2016). Effectiveness of six improved cookstoves in reducing household air pollution and their acceptability in rural Western Kenya. PLoS ONE. 11:e0165529. doi: 10.1371/journal.pone.0165529

Puzzolo, E., Pope, D., Stanistreet, D., Rehfuess, E. A., and Bruce, N. G. (2016). Clean fuels for resource-poor settings: A systematic review of barriers and enablers to adoption and sustained use. Environ. Res. 146, 218-234. doi: 10.1016/j.envres.2016.01.002

Quansah, R., Semple, S., Ochieng, C. A., Juvekar, S., Armah, F. A., Luginaah, I., et al. (2017). Effectiveness of interventions to reduce household air pollution and/or improve health in homes using solid fuel in low-and-middle income countries: A systematic review and meta-analysis. Environ. Int. 103, 73-90. doi: 10.1016/j.envint.2017.03.010

Ray, I., and Smith, K. R. (2021). Towards safe drinking water and clean cooking for all. Lancet Global Health. 9, e361. doi: 10.1016/S2214-109X(20)30476-9

Rooney, M. S., Arku, R. E., Dionisio, K. L., Paciorek, C., Friedman, A. B., Carmichael, H., et al. (2012). Spatial and temporal patterns of particulate matter sources and pollution in four communities in Accra, Ghana. Sci. Total Environ. 435-436, 107-114. doi: 10.1016/j.scitotenv.2012.06.077

Rupprecht, C. D. D., and Byrne, J. A. (2014). Informal urban greenspace: A typology and trilingual systematic review of its role for urban residents and trends in the literature. Urban Forest. Urban Green. 13, 597-611. doi: 10.1016/j.ufug.2014.09.002

Sanbata, H., Asfaw, A., and Kumie, A. (2014). Indoor air pollution in slum neighbourhoods of Addis Ababa, Ethiopia. Atmos. Environ. 89, 230-234. doi: 10.1016/j.atmosenv.2014.01.003

Sardeshpande, M., and Shackleton, C. (2020). Urban foraging: Land management policy, perspectives, and potential. PLOS ONE. 15:e230693. doi: 10.1371/journal.pone.0230693

Saulle, R., and La Torre, G. (2011). Good quality and available urban green spaces as good quality, health and wellness for human life. J. Public Health 34, 161-162. doi: 10.1093/pubmed/fdr090

Solomon, A. O. (2011). The Role of Households in Solid Waste Management in East Africa Capital Cities. Wageningen University. doi: 10.3920/978-90-8686-747-9

Stieb, D. M., Chen, L., Eshoul, M., and Judek, S. (2012). Ambient air pollution, birth weight and preterm birth: A systematic review and meta-analysis. Environ. Res. 117, 100-111. doi: 10.1016/j.envres.2012.05.007
Taha, H. (1997). Urban climates and heat islands: albedo, evapotranspiration, and anthropogenic heat. Energy Build. 25, 99-103. doi: 10.1016/S0378-7788(96)00999-1

Tefera, W., Asfaw, A., Gilliland, F., Worku, A., Wondimagegn, M., Kumie, A., et al. (2016). Indoor and outdoor air pollution-related health problem in ethiopia: review of related literature. Ethiopian J. Health Dev. 30, 5-16.

Teferi, E., and Abraha, H. (2017). "Urban Heat Island Effect of Addis Ababa City: implications of urban green spaces for climate change adaptation," in Climate Change Adaptation in Africa: Fostering Resilience and Capacity to Adapt. Climate Change Management, eds W. L. Filho, S. Belay, J. Kalangu, W. Menas, P. Munishi, K. Musiyiwa (Cham: Springer International Publishing) doi: 10.1007/978-3-319-49520-0_33

Tesfaye, F., Sturegård, E., Walles, J., Winqvist, N., Balcha, T. T., Karlson, S., et al. (2020). Alternative biomarkers for classification of latent tuberculosis infection status in pregnant women with borderline Quantiferon plus results. Tuberculosis 124:101984. doi: 10.1016/j.tube.2020.10 1984

Teshome, F. B. (2021). Municipal solid waste management in Ethiopia; the gaps and ways for improvement. J. Mater. Cycles Waste Manage. 23, 18-31. doi: 10.1007/s10163-020-01118-y

The World Bank (2021). Population growth (annual\%) - Sub-Saharan Africa. The World Bank.

Tomita, A., Vandormael, A. M., Cuadros, D., Di Minin, E., Heikinheimo, V., Tanser, F., et al. (2017). Green environment and incident depression in South Africa: a geospatial analysis and mental health implications in a resource-limited setting. Lancet Planetary Health 1, e152-e62. doi: 10.1016/S2542-5196(17)30063-3

Tsephel, S., Takama, T., Lambe, F., and Johnson, F. X. (2009). Why Perfect Stoves Are Not Always Chosen: A New Approach for Understanding Stove and Fuel Choice at the Household Level. Stockholm; Oxford: Household Energy Network.

UNEP (2014). World Urbanisation Prospects: The 2014 Revision, Highlights. New York: United Nations Environment Programme, Affairs DoEaS.

Vancampfort, D., Stubbs, B., Sallis, J. F., Nabanoba, J., Basangwa, D., Oyeyemi, A. L., et al. (2019). Associations of the built environment with physical activity and sedentary time in ugandan outpatients with mental health problems. J. Phys. Act. Health. 16, 243-250. doi: 10.1123/jpah.2018-0355

Walles, J., Tesfaye, F., Jansson, M., Balcha, T. T., Sturegård, E., Kefeni, M., et al. (2020). Tuberculosis infection in women of reproductive age: a cross-sectional study at antenatal care clinics in an Ethiopian City. Clin. Infect. Dis. 73, 203-210. doi: 10.1093/cid/ciaa561

Wang, Y., Cheng, K., Wu, W., Tian, H., Yi, P., Zhi, G., et al. (2017). Atmospheric emissions of typical toxic heavy metals from open burning of municipal solid waste in China. Atmos. Environ. 152, 6-15. doi: 10.1016/j.atmosenv.2016. 12.017

Worku, G., Teferi, E., and Bantider, A. (2021). Assessing the effects of vegetation change on urban land surface temperature using remote sensing data: The case of Addis Ababa city, Ethiopia. Remote Sensing App. Soc. Environ. 22:100520. doi: $10.1016 /$ j.rsase.2021.100520

World Health Organization (2010). WHO Guidelines for Indoor Air Quality: Selected Pollutants. Copenhagen: Regional Office for Europe.

World Health Organization (2013a). Health Risks of Air Pollution in Europe HRAPIE Project. Copenhage: WHO.

World Health Organization (2013b). Review of Evidence on Health Aspects of Air Pollution - REVIHAAP Project. Copenhagen: WHO.

World Health Organization (2016a). Ambient Air Pollution: A Global Assessment of Exposure and Burden of Disease. Geneva: WHO. doi: 10.17159/2410-972X/2016/v26n2a4

World Health Organization (2016b). Burning Opportunity: Clean Household Energy for Health, Sustainable Development, and Wellbeing of Women and Children. World Health Organization

World Health Organization (2016c). Urban Green Spaces and Health: A Review of Evidence. Copenhagen: Regional Office for Europe.

World Health Organization (2018). Ambient (Outdoor) Air Quality and Health [Internet]. World Health Organization.

Yessoufou, K., Sithole, M., and Elansary, H. O. (2020). Effects of urban green spaces on human perceived health improvements: Provision of green spaces is not enough but how people use them matters. PLOS ONE. 15:e0239314. doi: 10.1371/journal.pone.0239314 
Yip, F., Christensen, B., Sircar, K., Naeher, L., Bruce, N., Pennise, D., et al. (2017). Assessment of traditional and improved stove use on household air pollution and personal exposures in rural western Kenya. Environ. Int. 99, 185-191. doi: 10.1016/j.envint.2016.1 1.015

Yohannes, H., Soromessa, T., Argaw, M., and Dewan, A. (2020). Changes in landscape composition and configuration in the Beressa watershed, Blue Nile basin of Ethiopian Highlands: historical and future exploration. Heliyon 6:e04859. doi: 10.1016/j.heliyon.2020.e 04859

Conflict of Interest: The authors declare that the research was conducted in the absence of any commercial or financial relationships that could be construed as a potential conflict of interest.
Publisher's Note: All claims expressed in this article are solely those of the authors and do not necessarily represent those of their affiliated organizations, or those of the publisher, the editors and the reviewers. Any product that may be evaluated in this article, or claim that may be made by its manufacturer, is not guaranteed or endorsed by the publisher.

Copyright (๑) 2021 Flanagan, Mattisson, Walles, Abera, Eriksson, Balidemaj, Oudin, Isaxon and Malmqvist. This is an open-access article distributed under the terms of the Creative Commons Attribution License (CC BY). The use, distribution or reproduction in other forums is permitted, provided the original author(s) and the copyright owner(s) are credited and that the original publication in this journal is cited, in accordance with accepted academic practice. No use, distribution or reproduction is permitted which does not comply with these terms. 